\title{
Irrelevance of the choice of strategic variables in duopoly under relative profit maximization
}

\author{
Yasuhito Tanaka* \\ Faculty of Economics, Doshisha University, Japan
}

Received: 22 April 2013

Revised: 14 June 2013

Accepted: 17 June 2013

\begin{abstract}
We study the choice of strategic variables by firms in a duopoly in which two firms produce differentiated substitutable goods and each firm maximizes its relative profit that is the difference between its profit and the profit of the rival firm. We consider a two stage game such that in the first stage the firms choose their strategic variables and in the second stage they determine the values of their strategic variables. We show that when the firms maximize their relative profits, the choice of strategic variables is irrelevant to the outcome of the game in the sense that the equilibrium outputs, prices and profits of the firms are the same in all situations, and so any combination of strategy choice by the firms constitutes a sub-game perfect equilibrium in the two stage game. We assume that demand functions for the goods are symmetric and linear, the marginal costs of the firms are common and constant, and the fixed costs are zero.
\end{abstract}

Keywords: duopoly, relative profit maximization, choice of strategic variables

JEL Classification Codes: D43, L13

\section{Introduction}

We study the choice of strategic variables by firms in a duopoly in which two firms produce differentiated substitutable goods and each firm maximizes its relative profit that is the difference between its profit and the profit of the rival firm. We consider a two stage game such that in the first stage the firms choose their strategic variables, price or quantity, and in the second stage they determine the values of their strategic variables. We show that when the firms maximize their relative profits, the choice of strategic variables is irrelevant to the outcome of the game in the

\footnotetext{
*E-mail: yasuhito@mail.doshisha.ac.jp.

Citation: Tanaka, Y. (2013) Irrelevance of the choice of strategic variables in duopoly under relative profit maximization, Economics and Business Letters, 2(2), 75-83.
} 
sense that the equilibrium outputs, prices and profits of the firms are the same in all situations, and so any combination of strategy choice by the firms constitutes a sub-game perfect equilibrium in the two stage game. We assume that demand functions for the goods are symmetric and linear, the marginal costs of the firms are common and constant, and the fixed costs are zero.

In recent years, maximizing relative profit instead of absolute profit has aroused the interest of economists. From an evolutionary perspective, Schaffer (1989) demonstrates with a Darwinian model of economic natural selection that if firms have market power, profit-maximizers are not necessarily the best survivors. According to Schaffer (1989), a unilateral deviation from Cournot equilibrium decreases the profit of the deviator, but decreases the other firm's profit even more. On the condition of being better than other competitors, firms that deviate from Cournot equilibrium achieve higher payoffs than the payoffs they receive under Cournot equilibrium. In Vega-Redondo (1997), it is argued that, under a general equilibrium framework, if firms maximize relative profit, a Walrasian equilibrium can be induced.

On the other hand, Lundgren (1996) shows that by making managerial compensation depend on relative profits rather than absolute profits, the incentives for oligopoly collusion can be eliminated. Kockesen et. al. (2000) have shown that under some conditions a firm which strives to maximize relative profit will outperform a firm which maximizes absolute profit. Bolton and Ockenfels (2000) conducted an analysis considering an individual utility function that brings about a feeling of compassion toward an individual with a relatively lower material payoff and simultaneously brings about envy of other individuals with a higher material payoff.

As demonstrated by Matsumura, Matsushima and Cato (2009) evaluations of managers' performances are often based on their relative performance. Outperforming managers often obtain good positions in the management job markets. And the spiteful behavior as well as reciprocal behavior or altruistic behavior is closely related to the objective functions based on relative performance. The use of relative performance evaluation has been empirically supported by Gibbons and Murphy (1990).

In another paper Tanaka (2013) we have shown that in a duopoly with differentiated goods under linear demand functions when firms maximize relative profits, a Cournot equilibrium and a Bertrand equilibrium coincide. The result of this paper is an extension of that result.

In Section 3 we consider a case of absolute profit maximization, and in Section 4 we consider a case of relative profit maximization.

\section{The model}

There are two firms, A and B. They produce differentiated substitutable goods. Notation is as follows.

$$
\begin{aligned}
& x_{A}: \text { Output of Firm A } \\
& x_{B}: \text { Output of Firm B } \\
& p_{A}: \text { Price of the good of Firm A } \\
& p_{B}: \text { Price of the good of Firm B }
\end{aligned}
$$

The marginal costs of the firms are common, and equal $c>0$. There is no fixed cost.

The inverse demand functions of the goods produced by the firms are

$$
p_{A}=a-x_{A}-b x_{B},
$$


and

$$
p_{B}=a-x_{B}-b x_{A},
$$

where $a>c$ and $0<b<1 . x_{A}$ represents the demand for the good of Firm A, and $x_{B}$ represents the demand for the good of Firm B. The prices of the goods are determined so that demand of consumers for each firm's good and supply of each firm are equilibrated.

The ordinary demand functions for the goods of the firms are obtained from these inverse demand functions as follows,

and

$$
x_{A}=\frac{1}{1-b^{2}}\left[(1-b) a-p_{A}+b p_{B}\right]
$$

$$
x_{B}=\frac{1}{1-b^{2}}\left[(1-b) a-p_{B}+b p_{A}\right]
$$

From (2) we have

$$
x_{B}=a-p_{B}-b x_{A}
$$

Substituting this into (1) yields

$$
p_{A}=(1-b) a-\left(1-b^{2}\right) x_{A}+b p_{B} .
$$

(3) is the ordinary demand function for Firm B and (4) is the inverse demand function for Firm A when Firm A is a quantity setting firm and Firm B is a price setting firm. They are used in the next section.

We consider a two stage game. In the first stage the firms choose their strategic variables, price or quantity, and in the second stage they determine the values of their strategic variables.

\section{Absolute profit maximization}

In this section for reference we consider a case of absolute profit maximization. In this case each firm determines its strategic variable given the value of the rival firm's strategic variable so as to maximize their absolute profits.

\subsection{Price-quantity competition}

Assume that in the first stage of the game Firm A chooses the quantity, and Firm B chooses the price as their strategic variables. Using (4) the profit of Firm A is written as

$$
\pi_{A}=\left[(1-b) a-\left(1-b^{2}\right) x_{A}+b p_{B}\right] x_{A}-c x_{A} .
$$

And, using (3), the profit of Firm B is written as

$$
\pi_{B}=\left(a-p_{B}-b x_{A}\right)\left(p_{B}-c\right) .
$$

Firm A determines its output given the price of the good of Firm B, and Firm B determines the price of its good given the output of the good of Firm A so as to maximize their profits. The condition for profit maximization of Firm A is

$$
(1-b) a-2\left(1-b^{2}\right) x_{A}+b p_{B}-c=0 .
$$

And the condition for profit maximization of Firm B is

$$
a-2 p_{B}-b x_{A}+c=0 .
$$

From these conditions the equilibrium output of Firm A is obtained as follows, 


$$
x_{A}=\frac{(2-b)(a-c)}{4-3 b^{2}} .
$$

And the equilibrium price of the good of Firm $\mathrm{A}$ is

$$
p_{B}=\frac{(2+b)(1-b) a+\left(2+b-2 b^{2}\right) c}{4-3 b^{2}} .
$$

From (3) the equilibrium output of Firm B is derived as follows,

$$
x_{B}=a-p_{B}-b x_{A}=\frac{(2+b)(1-b)(a-c)}{4-3 b^{2}},
$$

and from (1) the equilibrium price of the good of Firm A is

$$
p_{A}=a-x_{A}-b x_{B}=\frac{\left(1-b^{2}\right)(2-b) a+\left(2+b-b^{2}-b^{3}\right) c}{4-3 b^{2}} .
$$

Denote the profits of Firm A (quantity setting firm) and B (price setting firm) by $\pi_{A}^{*}$ and $\pi_{B}^{*}$. Then,

$$
\pi_{A}^{*}=\frac{(2-b)^{2}\left(1-b^{2}\right)(a-c)^{2}}{\left(4-3 b^{2}\right)^{2}},
$$

and

$$
\pi_{B}^{*}=\left[\frac{(2+b)(1-b)(a-c)}{4-3 b^{2}}\right]^{2} .
$$

Interchanging $\mathrm{A}$ and $\mathrm{B}$, we can obtain the outcome of the second stage of the two stage game when Firm A is a price setting firm and Firm B is a quantity setting firm. The equilibrium profits of Firm A and B in that situation are

and

$$
\pi_{A}^{* * *}=\left[\frac{(2+b)(1-b)(a-c)}{4-3 b^{2}}\right]^{2},
$$

$$
\pi_{B}^{* *}=\frac{(2-b)^{2}\left(1-b^{2}\right)(a-c)^{2}}{\left(4-3 b^{2}\right)^{2}} .
$$

\subsection{Price-price competition}

Assume that both firms choose the price as their strategic variables. Then, the profits of Firm A and $\mathrm{B}$ are

$$
\pi_{A}=\frac{1}{1-b^{2}}\left[(1-b) a-p_{A}+b p_{B}\right]\left(p_{A}-c\right),
$$

and

$$
\pi_{B}=\frac{1}{1-b^{2}}\left[(1-b) a-p_{B}+b p_{A}\right]\left(p_{B}-c\right) .
$$

The conditions for profit maximization of Firm $\mathrm{A}$ and $\mathrm{B}$ are

$$
(1-b) a-2 p_{A}+b p_{B}+c=0,
$$

and

$$
(1-b) a-2 p_{B}+b p_{A}+c=0 .
$$

The equilibrium prices and outputs are 
and

$$
p_{A}=p_{B}=\frac{(1-b) a+c}{2-b}
$$

$$
x_{A}=x_{B}=\frac{a-c}{(2-b)(1+b)} .
$$

Denote the profits of Firm A and B in this case by $\hat{\pi}_{A}$ and $\hat{\pi}_{B}$. Then,

$$
\hat{\pi}_{A}=\hat{\pi}_{B}=\frac{(1-b)(a-c)^{2}}{(2-b)^{2}(1+b)} .
$$

\subsection{Quantity-quantity competition}

Assume that both firms choose the quantity as their strategic variables. Then, the profits of Firm A and $\mathrm{B}$ are

and

$$
\pi_{A}=\left(a-x_{A}-b x_{B}\right) x_{A}-c x_{A},
$$

$$
\pi_{A}=\left(a-x_{B}-b x_{A}\right) x_{B}-c x_{B} .
$$

The conditions for profit maximization of Firm A and B are

$$
a-2 x_{A}-b x_{B}-c=0
$$

and

$$
a-2 x_{B}-b x_{A}-c=0
$$

The equilibrium outputs and prices are

and

$$
x_{A}=x_{B}=\frac{a-c}{2+b},
$$

$$
p_{A}=p_{B}=\frac{a+(1+b) c}{2+b} .
$$

Denote the profits of Firm A and B in this case by $\bar{\pi}_{A}$ and $\bar{\pi}_{B}$. Then,

$$
\bar{\pi}_{A}=\bar{\pi}_{B}=\left(\frac{a-c}{2+b}\right)^{2} .
$$

\subsection{Choice of strategic variables}

Comparing $\pi_{A}^{*}$ with $\hat{\pi}_{A}$,

$$
\begin{aligned}
& \pi_{A}^{*}-\hat{\pi}_{A}=\frac{(2-b)^{2}\left(1-b^{2}\right)(a-c)^{2}}{\left(4-3 b^{2}\right)^{2}}-\frac{(1-b)(a-c)^{2}}{(2-b)^{2}(1+b)} \\
& =\left[\frac{2-b}{4-3 b^{2}}+\frac{1}{(2-b)(1+b)}\right]\left[\frac{2-b}{4-3 b^{2}}-\frac{1}{(2-b)(1+b)}\right]\left(1-b^{2}\right)(a-c)^{2} \\
& =\left[\frac{2-b}{4-3 b^{2}}+\frac{1}{(2-b)(1+b)}\right]\left[\frac{b^{3}}{(2-b)(1+b)\left(4-3 b^{2}\right)}\right]\left(1-b^{2}\right)(a-c)^{2}>0 .
\end{aligned}
$$

Comparing $\bar{\pi}_{B}$ with $\pi_{B}^{*}$, 


$$
\begin{aligned}
& \bar{\pi}_{B}-\pi_{B}^{*}=\left(\frac{a-c}{2+b}\right)^{2}-\left[\frac{(2+b)(1-b)(a-c)}{4-3 b^{2}}\right]^{2} \\
& =\left[\frac{1}{2+b}+\frac{(2+b)(1-b)}{4-3 b^{2}}\right]\left[\frac{1}{2+b}-\frac{(2+b)(1-b)}{4-3 b^{2}}\right](a-c)^{2} \\
& =\left[\frac{1}{2+b}+\frac{(2+b)(1-b)}{4-3 b^{2}}\right]\left[\frac{b^{3}}{(2+b)\left(4-3 b^{2}\right)}\right](a-c)^{2}>0 .
\end{aligned}
$$

Similarly we have

$$
\pi_{B}^{* *}>\hat{\pi}_{B}, \text { and } \bar{\pi}_{A}>\pi_{A}^{* *} .
$$

These results imply that in the first stage of the game the quantity strategy is a dominant strategy for the firms. Therefore, at the sub-game perfect equilibrium of the two stage game both firms choose the quantity as their strategic variables.

\section{Relative profit maximization}

In this section we consider a case of relative profit maximization. We denote the relative profit of Firm A by $\Pi_{A}$ and that of Firm B by $\Pi_{B}$.

\subsection{Price-quantity competition}

Assume that in the first stage of the game Firm A chooses the quantity, and Firm B chooses the price as their strategic variables. The relative profit of Firm A (or B) is the difference between its profit and the profit of Firm B (or A). Using (3) and (4), $\Pi_{A}$ and $\Pi_{B}$ are written as

$$
\begin{aligned}
& \Pi_{A}=\pi_{A}-\pi_{B} \\
& =\left[(1-b) a-\left(1-b^{2}\right) x_{A}+b p_{B}\right] x_{A}-c x_{A}-\left(a-p_{B}-b x_{A}\right)\left(p_{B}-c\right),
\end{aligned}
$$

and

$$
\begin{aligned}
& \Pi_{B}=\pi_{B}-\pi_{A} \\
& =\left(a-p_{B}-b x_{A}\right)\left(p_{B}-c\right)-\left[(1-b) a-\left(1-b^{2}\right) x_{A}+b p_{B}\right] x_{A}+c x_{A} .
\end{aligned}
$$

Firm A determines its output given the price of the good of Firm B, and Firm B determines the price of its good given the output of Firm A so as to maximize their relative profits. The condition for relative profit maximization of Firm $\mathrm{A}$ is

$$
\begin{aligned}
& (1-b) a-2\left(1-b^{2}\right) x_{A}+b p_{B}-c+b\left(p_{B}-c\right) \\
& =(1-b) a-(1+b) c-2\left(1-b^{2}\right) x_{A}+2 b p_{B}=0 .
\end{aligned}
$$

And the condition for relative profit maximization of Firm B is

$$
a-2 p_{B}-b x_{A}+c-b x_{A}=a-2 p_{B}-2 b x_{A}+c=0 .
$$

From (5) and (6) we obtain the equilibrium output of Firm A as follows,

$$
x_{A}=\frac{a-c}{2} .
$$

And the equilibrium price of the good of Firm B is derived as follows.

$$
p_{B}=\frac{(1-b) a+(1+b) c}{2} \text {. }
$$


Then, the equilibrium price of the good of Firm A and the equilibrium output of Firm B are

$$
p_{A}=\frac{(1-b) a+(1+b) c}{2} \text {, }
$$

and

$$
x_{B}=\frac{a-c}{2} .
$$

Therefore

$$
x_{A}=x_{B} \text { and } p_{A}=p_{B} .
$$

The equilibrium profits of the firms are obtained as follows,

$$
\pi_{A}^{*}=\pi_{B}^{*}=\frac{(1-b)(a-c)^{2}}{4} .
$$

\subsection{Price-price competition}

Assume that both firms choose the price as their strategic variables. The relative profits of Firm A and $\mathrm{B}$ are

and

$$
\Pi_{A}=\frac{1}{1-b^{2}}\left[(1-b) a-p_{A}+b p_{B}\right]\left(p_{A}-c\right)-\frac{1}{1-b^{2}}\left[(1-b) a-p_{B}+b p_{A}\right]\left(p_{B}-c\right),
$$

$$
\Pi_{B}=\frac{1}{1-b^{2}}\left[(1-b) a-p_{B}+b p_{A}\right]\left(p_{B}-c\right)-\frac{1}{1-b^{2}}\left[(1-b) a-p_{A}+b p_{B}\right]\left(p_{A}-c\right) .
$$

The conditions for relative profit maximization of Firm A and B are

$$
(1-b) a-2 p_{A}+(1+b) c=0 \text {. }
$$

and

$$
(1-b) a-2 p_{B}+(1+b) c=0 .
$$

Then, the equilibrium prices and outputs are

and

$$
p_{A}=p_{B}=\frac{(1-b) a+(1+b) c}{2}
$$

$$
x_{A}=x_{B}=\frac{a-c}{2} .
$$

The equilibrium profits of the firms are

$$
\hat{\pi}_{A}=\hat{\pi}_{B}=\frac{(1-b)(a-c)^{2}}{4} .
$$

\subsection{Quantity-quantity competition}

Assume that both firms choose the quantity as their strategic variables. The relative profits of Firm $\mathrm{A}$ and $\mathrm{B}$ are

and

$$
\Pi_{A}=\left(a-x_{A}-b x_{B}\right) x_{A}-c x_{A}-\left[\left(a-x_{B}-b x_{A}\right) x_{B}-c x_{B}\right],
$$

$$
\Pi_{B}=\left(a-x_{B}-b x_{A}\right) x_{B}-c x_{B}-\left[\left(a-x_{A}-b x_{B}\right) x_{A}-c x_{A}\right] .
$$

The conditions for profit maximization of Firm A and B are

$$
a-2 x_{A}-c=0 \text {, }
$$


and

$$
a-2 x_{B}-c=0
$$

Then, the equilibrium outputs and prices are

and

$$
x_{A}=x_{B}=\frac{a-c}{2},
$$

$$
p_{A}=p_{B}=\frac{(1-b) a+(1+b) c}{2} .
$$

The equilibrium profits of the firms are

$$
\bar{\pi}_{A}=\bar{\pi}_{B}=\frac{(1-b)(a-c)^{2}}{4} .
$$

\subsection{Choice of strategic variables}

From the arguments in the previous subsections we find that the equilibrium prices of the good of each firm in all four situations (price setting firm in price-quantity competition, quantity setting firm in price-quantity competition, price-price competition and quantity-quantity competition) are equal, the equilibrium outputs and the equilibrium profits of each firm in all situations are also equal.

Thus, any combination of strategy choice in the first stage of the game constitutes a sub-game perfect equilibrium in the two stage game.

\section{Note for a homogeneous good case}

The equilibrium when firms produce a homogenous good is defined as a limit of the previous results as $b$ approaches to 1 . Then, we have

$$
p_{A} \rightarrow c, \text { and } p_{B} \rightarrow c
$$

in each case. Thus, the equilibrium price in a homogeneous good case is equal to the equilibrium price in the perfectly competitive economy.

\section{Concluding Remarks}

In a two stage game of duopoly with the choice of strategic variables, price or quantity, and the choice of the levels of strategic variables, when the firms maximize their relative profits, the equilibrium outcomes (prices, outputs and profits) in all situations are equal. Thus, any combination of strategy choice by the firms constitutes a sub-game perfect equilibrium in the two stage game.

Relative profit maximization is another model of imperfect competition in addition to Cournot and Bertrand models. In monopoly and perfect competitive economy relative profit maximization coincides with absolute profit maximization.

Assuming that firms seek to maximize some weighted average of absolute and relative profits may be more realistic. In this paper, however, we have presented striking results under the assumption of genuine relative profit maximization.

We plan to research generalizations of the results of this paper to a duopoly with general demand and cost functions, and to an oligopoly. 
Acknowledgments. I am very grateful to the reviewers for their helpful comments on the original paper.

\section{References}

Bolton, G.E. and Ockenfels, A. (2000) A theory of equity, reciprocity, and competition, American Economic Review, 90, 166-193.

Gibbons, R. and Murphy, K.J. (1990) Relative performance evaluation for chief executive officers, Industrial and Labor Relations Review, 43, 30S-51S.

Kockesen, L., Ok, E.A. and Sethi, R. (2000) The strategic advantage of negatively interdependent preferences, Journal of Economic Theory, 92, 274-299.

Lundgren, C. (1996) Using relative profit incentives to prevent collusion, Review of Industrial Organization, 11, 533-550.

Matsumura, T., Matsushima, N. and Cato, S. (2009) Relative performance and R\&D competition, ISER Discussion Paper 0752, Institute of Social and Economic Research, Osaka University.

Schaffer, M.E. (1989) Are profit maximizers the best survivors?, Journal of Economic Behavior and Organization, 12, 29-45.

Tanaka, Y. (2013) Equivalence of Cournot and Bertrand equilibria in differentiated duopoly under relative profit maximization with linear demand", mimeo.

Vega-Redondo, F. (1997) The evolution of Walrasian behavior, Econometrica, 65, 375-384. 